\title{
Increasing Access to Safe Abortion Services Through Auxiliary Nurse Midwives Trained as Skilled Birth Attendants
}

\author{
KC NP, ${ }^{1}$ Basnett I, ${ }^{2}$ Sharma SK, ${ }^{2}$ Bhusal $\mathrm{CL},{ }^{3}$ Parajuli RR, ${ }^{2}$ Andersen $\mathrm{KL}^{4}$
}

${ }^{1}$ DoHS, Family Health Division, Teku

${ }^{2}$ Ipas Nepal, Teku

${ }^{3}$ Nepal Health Research Council, Ramshah Path

${ }^{4}$ Ipas, North Carolina

\section{Corresponding Author}

Sharad Kumar Sharma

Senior Monitoring and Evaluation Associate

Ipas Nepal

Email: sharmas@ipas.org

Citation

KC NP,Basnett I, Sharma SK, Bhusal CL, Parajuli RR, Andersen KL. Increasing Access to Safe Abortion Services Through Auxiliary Nurse Midwives Trained as Skilled Birth Attendants. Kathmandu Univ Med J 2011;36(4):260-66.

\author{
ABSTRACT \\ Background
}

The use of medical abortion methods was approved by Department of Health Services in 2009 and introduced in hospitals and a few primary health centres (PHCs). Access would increase if services were available at health post level and provided by auxiliary nurse midwives trained as skilled birth attendants. Evidence from South Africa, Bangladesh, Nepal and Vietnam show that mid-level health workers can provide medical abortion safely.

\section{Objectives}

To determine the best way to implement the new strategies of medical abortion into the existing health system of Nepal; and to facilitateits full-scale implementation, monitoring and evaluation.

\section{Methods}

An implementation research involving a baseline study, implementation phase and end line study was done in ten districts covering five development regions from July 2010 to June 2011. Both qualitative and quantitative methods were used.

\section{Results}

Of 1,799 medical abortion clients who received service, $46 \%$ were disadvantaged Janjati, $14 \%$ were Dalit, $42 \%$ were upper caste groups and rest were advantaged Janjati (7\%), Muslim (1\%) and others. $14 \%$ were referred by female community health volunteers and $56 \%$ were referred by others. Complication rate of $0.3 \%$ was well below acceptable levels. Condom use increased from $8 \%$ to $28 \%$ by the end of study. Use of Pills, Depo, intra uterine devices and Implants also increased, but use of long acting family planning methods was negligible.

\section{Conclusions}

This model should be replicated nationwide at health posts and sub-health posts where auxiliary nurse milwifes are available 24 hours/day. Focus should be given first to those areas where access is difficult, time consuming and costly.

\section{KEY WORD}

medical abortions, safe abortion services, skilled birth attendant

\section{INTRODUCTION}

Abortion was legalized in Nepal in 2002, but comprehensive abortion care (CAC) services were initiated only in 2004. From 2004 to 2010, 331 legal, safe abortion service (SAS) sites were approved by the government and 402,499 women had received safe and legal abortion services. ${ }^{1,2}$ Complications due to abortion remain one of the biggest causes of maternal mortality..$^{3-5}$

Until 2009, manual vacuum aspiration (MVA) was the only safe abortion technology in Nepal. Based on international evidence about the safety and efficacy of medical abortion
(MA), Family Health Division (FHD) of Department of Health Services (DoHS) developed the "MA Scale-Up Strategy and Implementation Guideline" in 2009.6,7 By the end of 2010, MA service was introduced in all 75 districts of Nepal but was limited to hospitals and a few primary health centres (PHCS).

A recent systematic review has found that home-based abortion is as safe as clinic-based abortion under certain conditions. ${ }^{8}$ A study conducted in South Africa confirms that midwives can provide high-quality abortion services 


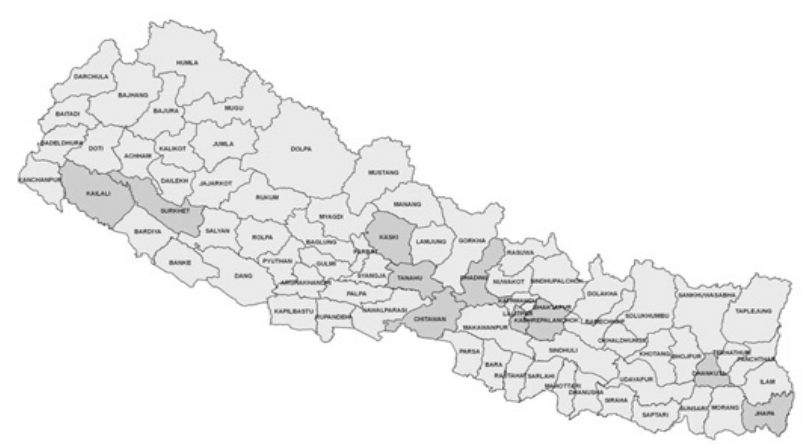

Figure 1. Implementing District in 2011.

Table 1. Samples health facilities selected for MA implementation in 2010.

\begin{tabular}{|lllll|}
\hline District & Hospital & PHC & HP & Total \\
\hline Jhapa & - & 6 & 4 & 10 \\
\hline Dhankuta & - & 2 & 6 & 8 \\
\hline Chitawan & 1 & 3 & 1 & 5 \\
\hline Kabhre & 1 & 4 & 7 & 12 \\
\hline Lalitpur & - & 4 & 3 & 7 \\
\hline Dhading & - & 2 & 7 & 9 \\
\hline Tanahu & - & 2 & 7 & 9 \\
\hline Kaski & - & 3 & 4 & 7 \\
\hline Surkhet & - & 4 & 2 & 6 \\
\hline Kailali & 1 & 5 & 4 & 9 \\
\hline Total & 3 & 35 & 45 & $83^{*}$ \\
\hline
\end{tabular}

*Even though 83 sites were selected for MA implementation, intervention was provided to 81 sites only

in the absence of physicians. ${ }^{9}$ In Nepal, a randomized equivalence study by WHO in five district hospitals in 20092010, showed that appropriately trained auxiliary nurse midwives (ANMs) could provide safe, effective MA services independent of doctors. ${ }^{10}$

In 2010, FHD and Ipas, initiated implementation research as a pilot project to test the feasibility of having ANMs, who had received skilled birth attendant (SBA) training, deliver MA services at PHCs and health posts (HPs).

\section{METHODS}

An implementation study was conducted as part of a pilot project from July 2010 to June 2011 and included baseline study, implementation of project and an end-line study. Both qualitative and quantitative methods were employed.

The pilot was done in 10 districts, covering five development regions (Fig 1). These areas were selected because they are conflict-affected, have low contraceptive prevalence rates,some have open border with India and have higher proportion of marginalized ethnic groups. ${ }^{11}$ The sites selected for MA intervention included hospitals, PHCs and HPs where at least one ANM with SBA training was currently working(Table 1).

A baseline study on implementation of MA in the selected districts was conducted in October and November 2010. Through it, information was collected about readiness of the facilities and workers to provide MA services. Both qualitative and quantitative information were collected through facility assessment, key informant interviews and facility service statistics.

Site performance score and provider performance score were the two important variables used in this study to examine the quality of MA services. Site quality was examined by observing and asking questions using a standard checklist, and then the scores were summarized for nine site performance standards. To meet the quality, MA sites had to fulfil all verification criteria given for each standard. The site performance standards and corresponding verification criteria were as follows:

1. Facility has adequate human resources (three verification criteria)

2. Facility has client friendly environment (nine verification criteria)

3. Facility has client friendly toilets (three verification criteria)

4. Facility has client friendly counselling room/space (eight verification criteria)

5. Facility has a full set of HMIS recording and reporting tools, job aide and used adequately (six verification criteria)

6. Facility has adequate examination room (13 verification criteria)

7. Sufficient contraceptive supplies are made in the facility (six verification criteria)

8. Facility has service delivery protocols and registers for keeping record (four verification criteria)

9. Instrument are properly decontaminated and processed (four verification criteria)

The main idea of having ANMs deliver MA services at rural PHCs and HPs is to increase access for poor rural women by bringing services closer to home, reducing travel time and cost, and having high-quality services delivered by trusted community level health providers. The intervention part of the project had three major components: developing a supportive, enabling environment at the district and health facility levels, building capacity of 120 ANMs and 30 SNs in MA service provision and delivering high-quality MA services to women by ANMs and SNs.

These interventions were implemented in different stages. The first stage was developing a supportive enabling environment at the district and health facility levels and included site strengthening, whole site orientation, and pharmacist orientation on SAS. The second stage was building capacity of ANMs and SNs in MA service provision. It included training of trainers in $\mathrm{MA}$, orientation to clinical mentors, and MA training to ANMs and SNs. The third stage 
Table 2. Summary of site performance standard criteria and standard met.

\begin{tabular}{|c|c|c|}
\hline SN & Performance Standards & $\begin{array}{l}\text { Standard } \\
\text { met }(n=76) \\
(\%)\end{array}$ \\
\hline 1 & The facility has adequate human resources & 94.7 \\
\hline 2 & The facility has client friendly environment & 34.2 \\
\hline 3 & The facility has client friendly toilet & 84.2 \\
\hline 4 & $\begin{array}{l}\text { The facility has client friendly counseling room/ } \\
\text { space }\end{array}$ & 67.1 \\
\hline 5 & The facility has a full set of HMIS recording tools & 68.4 \\
\hline 6 & The facility has adequate examination room & 21.1 \\
\hline 7 & $\begin{array}{l}\text { There are sufficient contraceptive supplies in the } \\
\text { facility }\end{array}$ & 82.9 \\
\hline 8 & $\begin{array}{l}\text { The facility has service delivery protocol and } \\
\text { record keeping }\end{array}$ & 68.4 \\
\hline 9 & $\begin{array}{l}\text { Instruments are properly decontaminated and } \\
\text { processed }\end{array}$ & 85.5 \\
\hline 10 & Medication supply & 97.4 \\
\hline
\end{tabular}

was actually delivering high quality MA services to women and included clinical mentoring to MA service providers, experience sharing workshop of clinical mentors, refresher training to MA service providers and district level review meeting.

Data collection for the end line study was done from May 4, 2011 to May 25, 2011. Site observation, analysis of client profile, and key informant interviews were the main methods of end line data collection. Overall objective of the end line evaluation study was to assess the feasibility, acceptability and effectiveness of MA service provision by ANMs at peripheral health facilities (HPs and PHCs) and to collect evidence-based feedback and recommendations for scale-up of services during the next phase. Caseload information of $81 \mathrm{MA}$ sites was collected. The evaluation team also visited 56 of the 81 facilities to collect qualitative information from service provider, clients and concerned stakeholders at the MA site and district health office.

\section{RESULTS}

Results from baseline study were used in refining the intervention approach. The baseline study revealed that most of the pilot sites did not have basic items (log book to register clients, pregnancy test kit, emergency contraception, IEC materials related to safe abortion and implant set) to implement MA service. Separate examination room to maintain privacy was available only in $71 \%$ PHCs and 53\% HPs. Knowledge about abortion and its policy and legal framework was not adequate among service providers but most of the SNs were interested to support ANMs as mentors. Unsafe practice to terminate pregnancy was prevalent in the community.

Table 2 shows a summary of findings obtained from site assessment checklist. Majority of facilities (95\%) had adequate human resources. Available services were client friendly only in $34 \%$ of the facilities. $67 \%$ of the facilities had client friendly counselling space. Similarly, only $21 \%$ of the facilities had separate examination room, although client friendly toilet facility was available in $84 \%$ of the sites. $68 \%$ of the facilities had maintained HMIS recording and reporting system. $83 \%$ of the pilot sites had enough contraceptive supply at the time of assessment and only $68 \%$ facilities hadMA service delivery protocols and proper record keeping system. Eighty six percent sites had used proper technique to decontaminate the instruments used in MA service delivery.

Table 3 shows that none of the facilities met all nine performance standards. Average site performance score was only seven. Score was highest (nine) in Dhading and lowest (five) in Lalitpur. Figure 2 shows the relationship between site performance score and mean number of clients served per provider by district. There was low level of correlation between the site performance and corresponding number of clients served per district (correlation coefficient of 0.23 ).

Table 3. Relationship between Site Performance Score and Medical Abortion Clients Served.

\begin{tabular}{|c|c|c|c|c|c|c|c|c|}
\hline Study District & No of MA Site & $\begin{array}{l}\text { No of Service } \\
\text { Provider }\end{array}$ & $\begin{array}{l}\text { Mean Site } \\
\text { Performance } \\
\text { Score }\end{array}$ & $\begin{array}{l}\text { Mean } \\
\text { Provider } \\
\text { Performance } \\
\text { Score }\end{array}$ & $\begin{array}{l}\text { Number of } \\
\text { MA Client } \\
\text { Served }\end{array}$ & $\begin{array}{l}\text { Mean no of } \\
\text { clients per } \\
\text { provider }\end{array}$ & $\begin{array}{l}\text { Mean no of } \\
\text { Clients per } \\
\text { MA Site }\end{array}$ & $\begin{array}{l}\text { Estimated } \\
\text { Abortion } \\
\text { Client }\end{array}$ \\
\hline Lalitpur & 11 & 11 & 5 & 8 & 86 & 8 & 36 & 458 \\
\hline Chitwan & 8 & 17 & 6 & 4 & 241 & 14 & 7 & 395 \\
\hline Kaski & 8 & 13 & 6 & 3 & 98 & 8 & 11 & 503 \\
\hline Dhankuta & 6 & 8 & 7 & 3 & 56 & 7 & 14 & 37 \\
\hline Kailali & 9 & 22 & 7 & 3 & 239 & 11 & 27 & 388 \\
\hline Kavre & 6 & 16 & 7 & 2 & 90 & 6 & 40 & 203 \\
\hline Jhapa & 9 & 23 & 8 & 4 & 398 & 17 & 11 & 537 \\
\hline Surkhet & 7 & 14 & 8 & 4 & 222 & 16 & 14 & 155 \\
\hline Tanahu & 8 & 18 & 8 & 3 & 113 & 6 & 28 & 125 \\
\hline Dhading & 8 & 19 & 9 & 3 & 256 & 13 & 27 & 182 \\
\hline Total & 80 & 161 & 7 & 5 & 1799 & 11 & 22 & 2983 \\
\hline
\end{tabular}




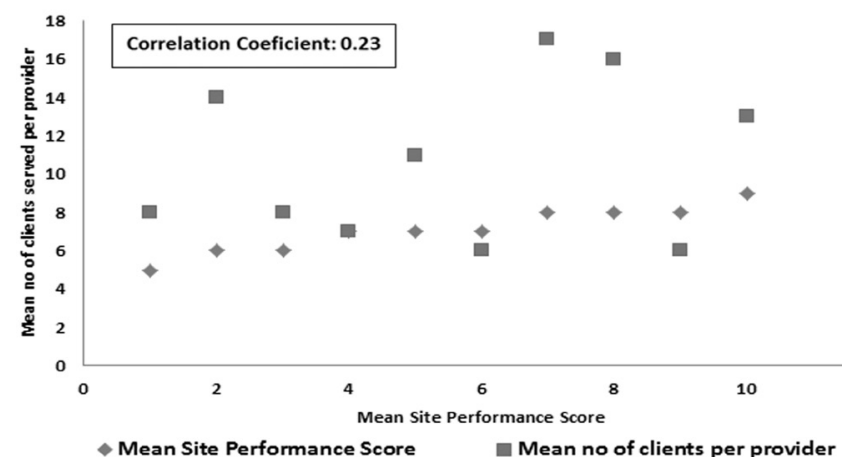

Figure 2. Relationship between site performance score and MA clients served.

As shown in Table 3, mean provider performance score was only five. The provider performance score ranges from minimum two (in Lalitpur and Kavre) and maximum four(in Chitwan, Jhapa, and Surkhet). As expected, Figure 3 indicates that there was high correlation (correlation coefficient: 0.69 ) between provider performance score and number of MA client served per provider.

We also examined the relationship between estimated abortion cases in the cluster (village development committee) and mean number of clients served per provider. The estimated abortion clients in a VDC was calculated assuming that three percent of the pregnancies are terminated using induced abortion (NDHS, 2006 shows that percentage of pregnancy lost due to induced abortion was six percent for urban area and two percent for rural areas). ${ }^{11}$ Fig 4 indicates that there was moderate level of correlation between estimated abortion cases in the cluster and number of MA client served per provider.

Information of 1,799 MA clients who received service from pilot sites during the implementation period was obtained from log books. 46\% were from disadvantaged Janjati group, $14 \%$ were Dalit, $42 \%$ were upper caste groups and rest were advantaged Janjati (seven percent), Muslim (one percent) and others (Table 4). As 63\% women belonged to Dalit, minority and disadvantaged groups, MA service was accessible to all tiers of the community.

The mean age of women receiving MA service was 28 years. $32 \%$ the MA clients were under the age 25 and $61 \%$ of the clients were of age between 25 to 39 years, indicating that unintended pregnancy resulting in abortion is high among younger women.

As seen in Table 4, 27\% of MA clients had never attended school. About a quarter (31\%) had primary level of education and $34 \%$ had level of education between six to 12 grades. More than two-third (68\%) of the clients had two or less children, suggesting that these women may be using abortion instead of contraception.

About $14 \%$ of the MA clients were referred by FCHVs and more than a half $(56 \%)$ were referred by others (other than
Table 4. Background Characteristics of Women Receiving Medical Abortion Services.

\begin{tabular}{|c|c|}
\hline Background Characteristics & Number (\%) \\
\hline Ethnicity & $1,799(100)$ \\
\hline Dalit & $246(13.67)$ \\
\hline Disadvantaged Janjati & $581(45.97)$ \\
\hline Disadvantaged non-dalit tarai & $33(1.83)$ \\
\hline Muslim \& Churoute & $23(1.30)$ \\
\hline Advantaged Janjati & $130(7.23)$ \\
\hline Upper Caste Group & $762(42.36)$ \\
\hline Other & $24(1.33)$ \\
\hline Age Group & $1,799(100)$ \\
\hline$<20$ & $136(7.59)$ \\
\hline $20-24$ & $463(25.82)$ \\
\hline $25-29$ & $527(29.39)$ \\
\hline $30-34$ & $364(20.30)$ \\
\hline $35-39$ & $208(11.60)$ \\
\hline $40-44$ & $81(4.52)$ \\
\hline$>44$ & $14(0.78)$ \\
\hline Education & $1,799(100)$ \\
\hline No education & $479(26.63)$ \\
\hline 1-5grade & $566(31.46)$ \\
\hline $6-12$ grade & $606(33.69)$ \\
\hline$>12$ grade & $148(8.23)$ \\
\hline Living Children & $1,799(100)$ \\
\hline No child & $184(10.23)$ \\
\hline One child & $373(20.73)$ \\
\hline Two children & $671(37.30)$ \\
\hline Three children & $317(17.62)$ \\
\hline Four children & $145(8.06)$ \\
\hline More than four children & $109(6.06)$ \\
\hline Referred By & $1,799(100)$ \\
\hline Referred by FCHV & $249(13.84)$ \\
\hline Referred by provider & $506(28.13)$ \\
\hline Referred by other & 999 (55.53) \\
\hline Missing & $45(2.50)$ \\
\hline Total & $1,799(100)$ \\
\hline
\end{tabular}

FCHV and health personnel), suggesting that awareness of access to MA was diffused throughout the community via different means.

As shown in the Table $5,98 \%(1,759$ out of 1,799$)$ of the clients who used MA were followed up after two weeks and 40 clients were not followed up. The logbook analysis further showed that the MA was successful in $98 \%$ of clients $(1,759)$. Remaining 20 (1.1\%) clients, who experienced incomplete abortion, were managed by MVA. Six $(0.3 \%)$ clients experienced complications after MA. Three out of six women who experienced complications after MA were treated with oral antibiotics and other three women received blood transfusion. 
Table 5. Distribution of MA clients in 10 districts according to service status, January 2011- June 2011, Nepal.

\begin{tabular}{|c|c|c|c|c|c|}
\hline MA service status of clients & HP & PHC & $\mathrm{MCH}^{* *}$ Clinic & Hospital* & Total \\
\hline Number of clients benefiting from MA services & 712 & 1017 & 32 & 38 & 1799 \\
\hline Number of client successfully followed up & 711 & 983 & 32 & 33 & 1759 \\
\hline Percent of client successfully followed up & 99.8 & 96.7 & 100 & 86.8 & 97.8 \\
\hline Number of clients lost to follow up & 1 & 34 & 0 & 5 & 34 \\
\hline Percent of client lost to followed up & 0.2 & 3.3 & 0 & 13.2 & 2.2 \\
\hline Number clients successfully completing MA & 698 & 968 & 32 & 33 & 1731 \\
\hline Percent of clients successfully completing MA & 98.1 & 95.2 & 100 & 86.8 & 96.2 \\
\hline Number of unsuccessful medical abortion (MVA done) & 8 & 12 & & & 20 \\
\hline Percent of unsuccessful medical abortion (MVA done) & 1.1 & 1.2 & & & 1.1 \\
\hline \multicolumn{6}{|l|}{ Complication } \\
\hline Number of clients requiring blood transfusion & 3 & 0 & & & 3 \\
\hline Percent of clients requiring blood transfusion & 0.4 & 0 & & & 0.2 \\
\hline Number clients with suspected infection & 0 & 3 & & & 3 \\
\hline Percent of clients with suspected infection & 0 & 0.3 & & & 0.2 \\
\hline
\end{tabular}

Table 6. Distribution of MA clients in 10 districts according to service utilization status, January 2011- June 2011, Nepal.

\begin{tabular}{|ll}
\hline $\begin{array}{l}\text { Indicators } \\
\text { Option for route of Misoprostol administration }\end{array}$ & $\begin{array}{l}\text { Fre qu e n cy } \\
(\%)\end{array}$ \\
\hline Vaginal & $640(35.6)$ \\
\hline Sublingual & $1159(64.4)$ \\
\hline Total & $1799(100.0)$ \\
\hline Option for Misoprostol administration & \\
\hline Clinic & $502(27.9)$ \\
\hline Home & $1297(72.1)$ \\
\hline Total & $1799(100.0)$ \\
\hline Follow up & \\
\hline In person & $1429(72.5)$ \\
\hline By Telephone & $370(18.8)$ \\
\hline Total & $1799(100.0)$ \\
\hline
\end{tabular}

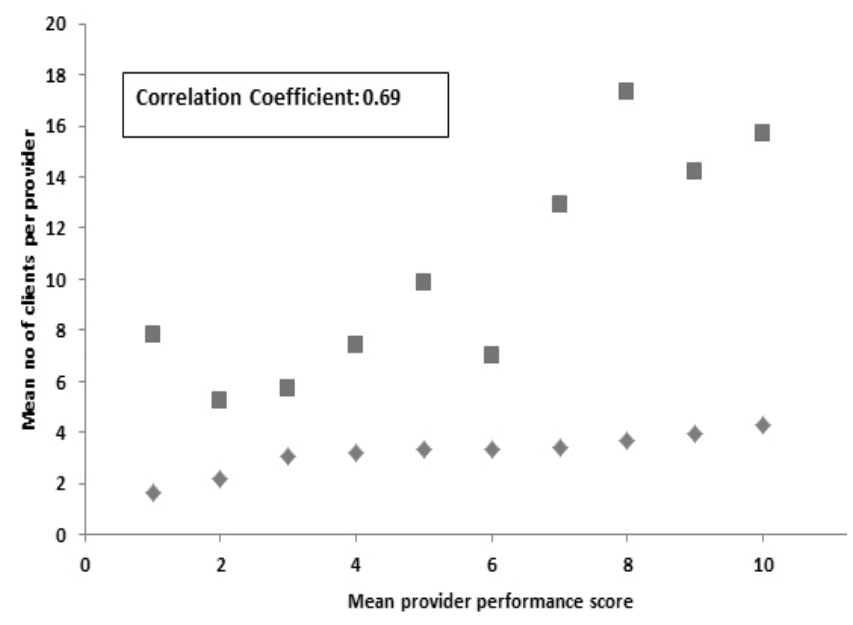

Figure 4. Relationship between provider performance score and MA clients served.

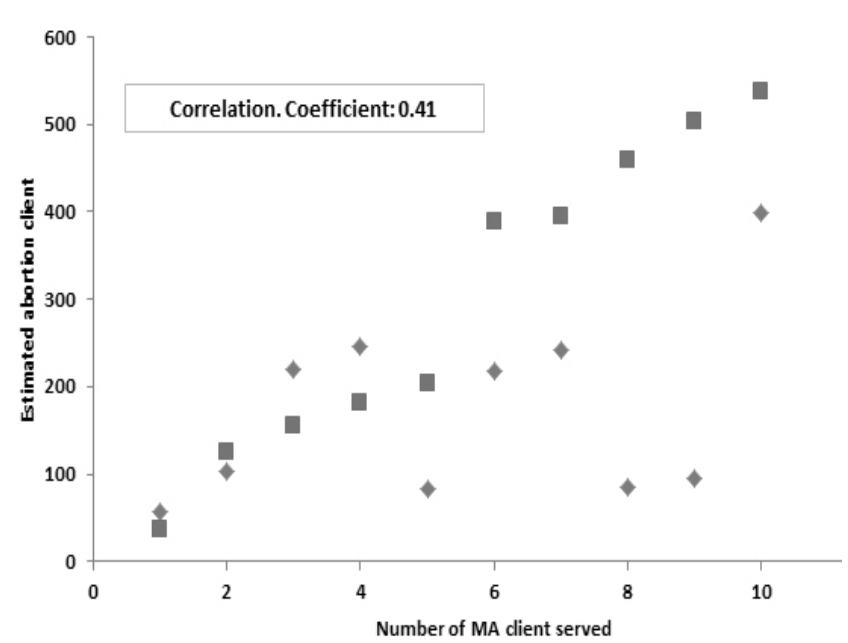

Figure 3. Relationship between estimated abortion cases and total MA service provided

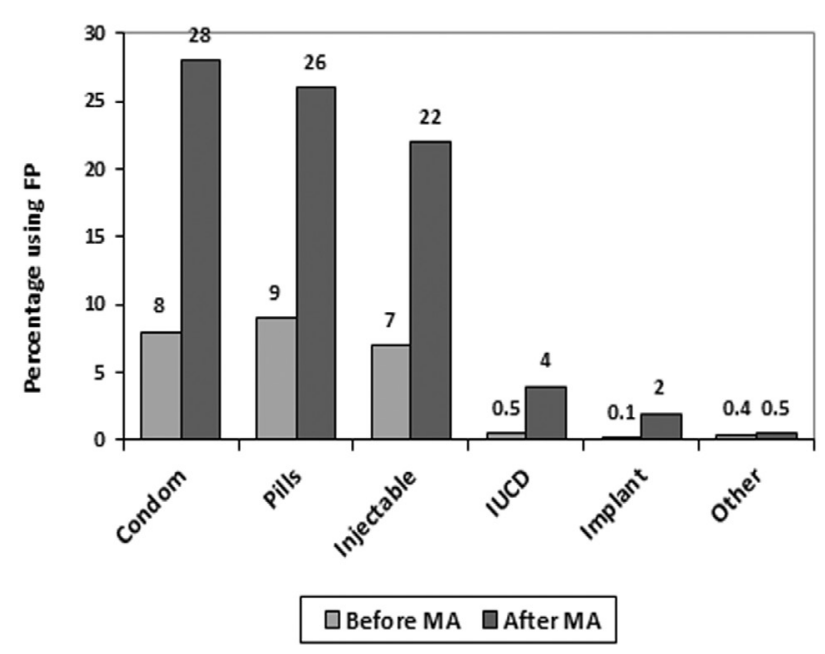

Figure 5. Percentage of women using of family planning methods before and after MA procedure. 
Table 6 indicates that $72 \%$ of the clients preferred using Misoprostol at home. $64 \%$ of them preferred sublingual administration of Misoprostol over vaginal administration. Similarly, most of the clients preferred in-person follow-up over phone follow-up.

Figure 5 shows the use of family planning method before and after medical abortion. The use of condoms significantly increased from $8 \%$ to $28 \%$. Use of Pills, Depo, IUDs and Implants were also increased after MA. However, the use of long acting family planning methods is negligible. The review of client profiles also indicates percentage of women not using any FP after MA was significantly reduced.

Findings from the end-line study show that major achievements of the pilot project were that the MA service has been expanded from district centre up to the rural community. One MA client said, "The service is very closeby and I did not need to travel by vehicle, saving money and time. My case was kept confidential. The nurse provided me with the tablets, I used them, and it just felt like a normal menstrual period."

Service providers and other stakeholders at the district were well aware about MA service and its benefit to the community's women. The project sites received good support from DHOs. The providers were confident in providing MA service, which helped to increase utilization and created positive environment at the community. Few life threatening complications seen among MA clients indicated that good quality services were provided.

MA service providers perceive that NRs. 500 charged for MA service was reasonable for most of the women. However, they suggest that some provision of free or minimum charge for poor women will increase access to all women.

\section{DISCUSSION}

As MA is safe, effective and can be carried out at minimal cost, it has significant potential to increase access to safe abortion in remote areas. ${ }^{12,13}$ This MA pilot showed extremely favourable outcomes over a very short implementation timeframe of only 12 months.

Safe and effective use of affordable MA depends upon ensuring that health care providers are trained, referral mechanisms and monitoring systems are in place and services are decentralized through task shifting, that is provision of MA from doctors to mid-and low-level providers such as SNs and ANMs. ${ }^{12}$ In South Africa, it was found that midwives can provide high-quality abortion services in the absence of physicians. ${ }^{9}$ Similarly, early abortion provided by female welfare volunteers without formal midwifery training was found to be safe in Bangladesh. ${ }^{14}$ Warriner, et al. performed a randomized, controlled trial comparing rates of abortion complications among women who were treated by government-trained mid-level providers versus physicians in South Africa and Vietnam. The study found that with appropriate training, the mid-level providers were able to provide uterine evacuation (UE) services using MVA as safely as physicians. ${ }^{15}$ While these studies focused on quality mid-level provision of abortion using MVA, similar patterns have been seen for the less technologically intensive provision of abortion using MA; for example, the randomized 2009 - 2010 equivalence study in Nepal showed that trained ANMs did provide safe, effective MA services in the absence of physicians. ${ }^{10}$

Quality indicators including complication follow-up and post MA contraception utilization rates showed that with the proper training and support, ANMs were capable of providing high-quality MA services, on par with those delivered by nurses and other providers at higher-level facilities. The complication rate of $0.3 \%$ was low, compared with $0.6 \%$ during the initial piloting of MA services in 2009 and $2 \%$, which is generally considered an acceptable complication rate. $6,16,17$ The high follow-up rate of $98 \%$ exceeded the follow up rate of $96 \%$ when MA was initially piloted in six districts of Nepal in 2009.The post MA contraception utilization rate of $81 \%$ was high. The rate of successful MA was $98.9 \%$ compared to the initial MA pilot rate of $96.1 \%$ in $2009 .{ }^{6} \mathrm{MA}$ services were perceived by all respondent groups in the evaluation to be accessible, simple, effective, and of good quality. $78 \%$ of MA clients interviewed $(n=62)$ evaluated the service they received as good or very good, with confidentiality of service cited as the primary factor. Service waiting times were reasonable, with $69 \%$ waiting 30 minutes or less. Overall, the 56 pilot sites that were evaluated in the 10 districts had smoothly functioning MA services, well supported by local and district stakeholders, and by peripheral health facility staff, FCHVs and medical abortion clients.

\section{CONCLUSION}

At the end of this pilot, MA services by ANMs are up and running at 81 peripheral facilities (PHCs and health posts) in 10 districts. Out of the 120 ANMs trained in MA service provision, 115 are actively providing MA services. Overall, all 56 pilot sites in 10 districts are smoothly providing MA services, well supported by local and district stakeholders, and widely accepted by peripheral health facility staff, FCHVs and medical abortion clients. Taking time and resources to create a supportive, enabling environment at district and facility levels was crucial to the pilot's success.

We recommend the use of a blended learning approach for training ANMs in MA service provision, providing theoretical readings in advance, and focusing trainings on hands-on practical skill-building on uterine size estimation, counselling, and contraceptive use. Also, select training sites with high case-loads to ensure that trainees have sufficient individual practice. MA drugs should be provided in routine supply system of essential drugs, guidelines and uniform provisions should be developed for free or reduced fee services and long term family planning methods along with MA should be strengthened. 
We suggest that this model should be replicated nationwide at health posts and sub-health posts where ANMs are available 24 hours/day (e.g. birthing centres). Focus should be given first to those areas where access is more difficult, time consuming and costly, such as hilly regions.

\section{REFERENCES}

1. Nepal Government. Annual Report, 2009/2010. Kathmandu:Department of Health Services;2010.

2. Basnet I, Clapham S, Shakya G, McCall M. Evolution of the Postabortion Care Program in Nepal: The Contribution of a National Safe Motherhood Project. International Journal of Gynecology and Obstetrics 2004;86:98-108.

3. Pradhan A, Suvedi BK, Barnett S, Sharma SK, Puri M, Poudel P, et al. Nepal maternal Mortality and Morbidity Study 2008/2009.Family Health Division, Department of Health Services, Ministry of Health and Population, Government of Nepal, Kathmandu, Nepal.2010.

4. World Health Organization. Unsafe abortion: global and regional estimates of the incidence of unsafe abortion and associated mortality in 2008. Geneva:WHO;2008. [Available from - http://www. who.int/publications/2011/978924150118_eng.pdf]

5. Hoj L, da Silva D, Hedegaard K. Maternal mortality: only 42 days? BJOG 2003;110:995-1000.

6. World Health Organization. Safe Abortion: Technical and Policy Guidance for Health Systems. Geneva,Switzerland:WHO;2003.

7. Nepal Government. Medical Abortion Scaling Up Strategy and Implementation Guideline. Kathmandu:Family Health Division;2009 November.

8. Ngo TD, Park MA, Shakura H, Freea C. Comparative effectiveness, safety and acceptability of medical abortion at home and in a clinic: a systematic review. Bull World Health Organ 2011;89:360-70.

9. Dickson-tettehK,BillingsDL.Abortion Care Services Provided by Registered Midwives in South Africa. International Family Planning Perspectives 2002:28:144- 150.

10. Warriner IK, Wang D, Huong NT, Thapa K, Tamang A, Shah I, Baird D, Meirik O. Can midlevel health-care providers administer early medical abortion as safely and effectively as doctors? A randomized controlled equivalence trial in Nepal. Lancet 2011;377:2300-34.
11. Nepal Government. Nepal Demographic And Health Survey 2006. Kathmandu, Nepal and Calverton, Maryland, USA:Ministry of Health and Population, New ERA, Nepal and Macro International Inc., USA;2006.

12. Gordon P, Boler T, Burgin J, Brett T. What Women Want:meeting the global demand for medical abortion. London:MarieStopes International;2010. [Available from - http://www.mariestopes.org/ documents/publications/What-Women-Want.pdf]

13. Grossman D. Medical methods for first trimester abortion: RHL commentary. The WHO Reproductive Health Library. Geneva:World Health Organization;2004 Sept.

14. Chowdhury RI, IslamMA, AkhterHH, Chakraborty N. Analysis of postpartum complications in relation to selected delivery characteristics in rural Bangladesh. Journal of Health and Population in Developing Countries 2004;21:1-10.

15. Warriner IK, Meirik O, Hoffman M, Morroni C, Harries J, My Huong NT, et al. Rates of Complication in First-Trimester Manual Vacuum Aspiration Abortion Done by Doctors and Mid-level Providers in South Africa and Vietnam: A Randomized Controlled Equivalence Trial. Lancet 2006;368:1965-72.

16. Greenslade FC, WinklerJ, Leonard AH. A framework for evaluating the quality of postabortion care services. In: Huntington D, ed. Advances and challenges in postabortion care: summary report of a global meeting. New York, Population Council. 1998.

17. Sannon C, Brothers LP, Philip NM, Winikoff B. Infection after medical abortion: a review of the literature. Contraception 2004;70:183-90. 